\title{
HUBUNGAN PENGETAHUAN,SIKAP, DAN PAPARAN INFORMASI DENGAN PERAN SUAMI DALAM PENCEGAHAN BAYI BERAT LAHIR RENDAH DI PUSKESMAS II SUMBANG DAN KEDUNGBANTENG
}

\author{
RELATIONSHIP KNOWLEDGE, ATTITUDE AND EXPOSURE OF \\ INFORMATION WITH THE ROLE OF HUSBAND IN LOW BIRTH \\ WEIGHT PREVENTION IN SUMBANG II AND KEDUNGBANTENG \\ PUBLIC HEALTH CENTER
}

\author{
Setiyowati Rahardjo, Erna Kusumawati, Ibnu Zaki \\ Jurusan Kesehatan Masyarakat Fakultas Ilmu-ilmu Kesehatan \\ Universitas Jenderal Soedirman
}

\begin{abstract}
Prevalence of Low Birth Weight (LBW) in the working area of Sumbang II Public Health Center (PHC) (7.1\%) and Kedungbanteng PHC in 2015 is still a health problem (5.57\%). Efforts that can be done to prevent the occurrence of $L B W$ is to optimize the role of the husband. The purpose of this study is to determine the relationship between knowledge, attitudes and access information with the role of husband in prevention of $L B W$. This type of research is quantitative cross-sectional. The population in this study were all husbands of mothers who had babies aged 0 3 months and recorded in Sumbang II PHC and Kedungbanteng, Samples were selected with cluster random sampling of 100 respondents. The data were collected by interview using questionnaire. Data analysis included univariate anallisis to describe each variable, bivariate with chi square and multivariate test using logistic regression. The univariate result showed that most respondents had good prevention role of $L B W(70 \%)$, good knowledge (61\%), had supportive attitude (55\%), had good information access (57\%). Bivariate analysis showed related variables Namely knowledge and access to information. Multivariate analysis shows the variables that influence is access to information.Public Health Center to optimize the dissemination of information about $L B W$.
\end{abstract}

Keywords: LBW, Role of Husband, Knowledge, Attitude, Access information

\section{ABSTRAK}

Prevalensi Bayi Berat Lahir Rendah (BBLR) pada tahun 2015 di wilayah kerjaPuskesmas II Sumbang $(7,1 \%)$ dan Kedungbanteng masih menjadi masalah kesehatan $(5,57 \%)$. Upaya yang dapat dilakukan untuk mencegah kejadian BBLR adalah dengan mengoptimalkan peran suami. Tujuan penelitian ini adalah untuk mengetahui hubungan antara pengetahuan,sikap dan akses informasi dengan peran suami dalam pencegahan BBLR. Jenis penelitian ini adalah kuantitatifcross-sectional.Populasidalam penelitian ini adalah seluruh suami dari ibu yang mempunyai bayi berusia 0-3 bulan dan tercatat di Puskesmas II Sumbang dan Kedungbanteng, Sampel dipilih dengan cluster random sampling sebanyak 100 responden. Pengambilan data dilakukandengan wawancara menggunakan kuesioner. Analisis data meliputi analisis univariat untuk menggambarkan masing-masing variabel, bivariat dengan uji chisquare dan multivariate menggunakan regresi logistik. Hasil univariat menunjukkan bahwa sebagian besar respondenmempunyai peran pencegahan BBLR yang baik $(70 \%)$, berpengetahuan baik $(61 \%)$, memiliki sikap yang mendukung (55\%), memiliki akses informasi yang baik (57\%).Analisis bivariat menunjukkan variabel yang berhubungan yaitu pengetahuan dan akses informasi.Analisis multivariat menunjukkan variabel yang mempengaruhi adalah akses informasi.Bagi pihak Puskesmas agar lebih mengoptimalkan penyebarluasan informasi tentang BBLR.

Kata kunci :BBLR, Peran Suami, Pengetahuan, Sikap, Akses informasi. 
PENDAHULUAN

Bayi Berat Lahir Rendah (BBLR) merupakan faktor utama dalam peningkatan mortalitas, morbiditas dan disabilitas neonatus, bayi dan anak serta memberikan dampak jangka panjang terhadap kehidupannya di masa depan (Proverawati dan Siti, 2010). Prevalensi global BBLR adalah $15,5 \%$ yang berjumlah sekitar 20 juta BBLR lahir setiap tahun dan 96,5\% dari mereka berasal dari negara berkembang (WHO, 2013). Setiap tahun, 1,1 juta bayi meninggal akibat komplikasi dari kelahiran prematur yang salah satunya adalah bayi berat lahir rendah (BBLR). Secara keseluruhan, diperkirakan bahwa $15 \%$ sampai $20 \%$ dari semua kelahiran di seluruh dunia adalah berat badan lahir rendah, yang mewakili lebih dari 20 juta kelahiran per tahun (WHO, 2014).

Hasil Riskesdas 2013 prevalensi BBLR di Indonesia sebesar 10,2\%, adapun prevalensi BBLR untuk Provinsi JawaTengah adalah 10\% (Kemenkes, 2013). Jumlah BBLR di Kabupaten Banyumas tahun 2015 adalah 5,57\% dari kelahiran hidup (Dinkes
Banyumas, 2016). Jumlah kasus BBLR yang dilaporkan di Puskesmas II Sumbang tahun 2015 sebanyak 51 $(7,1 \%)$ dari 725 kelahiran hidup dengan jumlah kasus BBLR pada persalinan aterm sebanyak $21(41 \%)$ (Puskesmas II Sumbang, 2016). Kasus BBLR di Puskesmas Kedungbanteng pada tahun 2015 sebesar $52(5,2 \%)$ kasus dari 982 kelahiran hidupdengan jumlah kasus BBLR pada persalinan aterm di Puskesmas Kedungbanteng sebanyak 37 (71\%)

(Puskesmas Kedungbanteng, 2016).Berdasarkan Depkes RI (2008) bayi berat lahir rendah (BBLR) menjadi masalah kesehatan masyarakat apabila prevalensinya $\geq 5 \%$, hal tersebut menunjukkan bahwa kasus BBLR di wilayah kerja Puskesmas Kedungbanteng masih menjadi masalah kesehatan.

Upaya yang dapat dilakukan untuk mencegah kejadian BBLR adalah dengan menjaga kesehatan ibu dari sebelum masa kehamilan hingga saat bayi dilahirkan.Kesehatan ibu sangat erat kaitannya dengan peran suami.Ketika suami terlibat selama kehamilan, perilaku kesehatan negatif ibu 
berkurang dan risiko kelahiran prematur, berat lahir rendah dan pembatasan pertumbuhan janin berkurang (BKKBN, 2007). Lewis, et al., (2015) menyatakan masih adanya kepercayaan tradisional yang mempengaruhi keterlibatan laki-laki dalam kesehatan ibu dan persalinan aman, kepercayaan tersebut yaitu masalah kehamilan dan persalinan hanya menjadi tugas perempuan. Alawiyah (2014) menyatakan ada hubungan antara dukungan suami dengan kelengkapan kunjungan AntenatalCare (ANC) pada ibu hamil trimester III di Puskesmas Mergangsan $(\mathrm{p}<0,05)$.

Peran suami dalam pencegahan BBLR dipengaruhi beberapa faktor, antara lain faktor predisposisi, faktor pendukung dan faktor penguat. Faktor predisposisi meliputi pengetahuan, sikap, nilai, kepercayaan dan lain sebagainya. Faktor pendukung meliputi keterjangkauan pelayanan kesehatan dan akses informasi. Faktor penguat meliputi peran tokoh serta peran tenaga kesehatan (Notoatmodjo, 2010.) Penelitian Ditekemena, et al., (2012) menyatakan bahwa terdapat hubungan antara faktor sosial demografis (pengetahuan dan pendapatan suami), faktor sosiologis (keyakinansikap dan komunikasi suami-istri) dengan peran suami dalam menjaga Kesehatan Ibu dan Anak (KIA) di sub-Saharan Afrika.Berdasarkan uraian tersebut maka penulis ingin mengetahui hubungan pengetahuan, sikap, dan paparan informasi dengan peran suami dalam pencegahan BBLR di wilayah kerja Puskesmas II Sumbang dan Kedungbanteng.

\section{METODE PENELITIAN}

Penelitian ini merupakan jenis penelitian observasional analitik dengan pendekatan cross sectional. Populasi dalam penelitian ini adalah seluruh suami dari ibu yang mempunyai bayi berusia 0-3 bulan dan tercatat di Puskesmas Kedungbanteng dan Puskesmas II Sumbang.. Pemilihan sampel dilakukan dengan metode clusterrandom sampling didapatkan sampel sebesar 100 responden.

Variabel dependen dalam penelitian ini adalah peran suami dalam pencegahan BBLR sedangkan variabel independen dalam penelitian ini meliputi pengetahuan suami, 


$\begin{array}{lrrr}\text { sikap suami dan } & \text { akses } & \text { analisis multivariat menggunakan uji } \\ \text { informasi.Pengambilan } & \text { data } & \text { regresi logistik. } \\ \text { dilakukan } & \text { dengan } & \text { wawancara } & \end{array}$
menggunakan kuesioner. Analisis univariat, menggunakan analisis HASIL DAN PEMBAHASAN

distribusi frekuensi dari masing Karakteristik responden di masing variable..Analisis bivariat Wilayah kerja Puskesmas II Sumbang dan Kedungbanteng dapat menggunakan uji chi-square serta dilihat pada tabel 1 berikut.

Tabel 1. Gambaran Karakteristik Responden di Wilayah Kerja Puskesmas II Sumbang dan Kedungbanteng tahun 2016

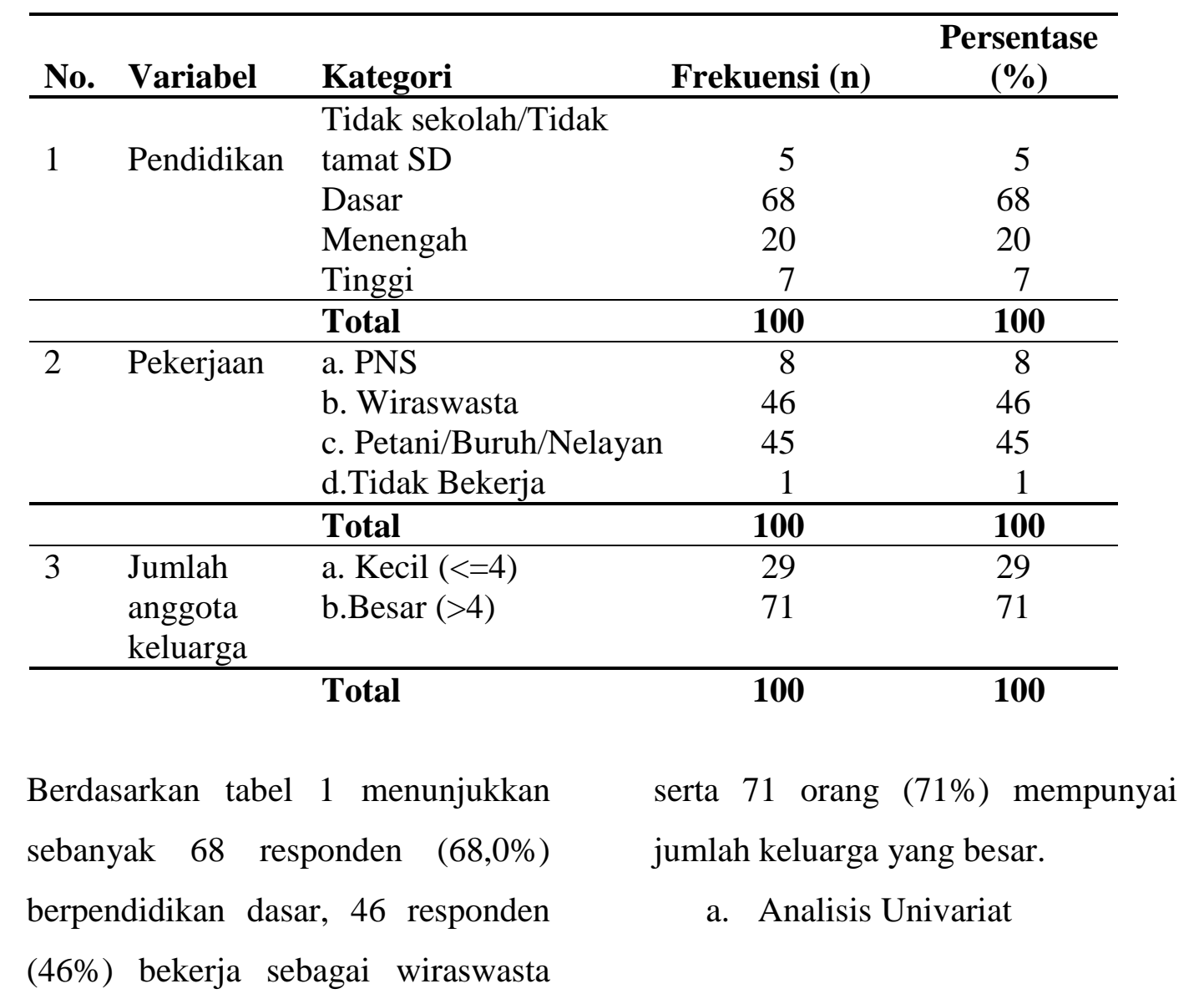


Tabel 2. Distribusi frekuensi variabel dependen dan independen di Puskesmas II Sumbang dan Baturaden

\begin{tabular}{|c|c|c|c|}
\hline No & Variabel & Jumlah & Persentase \\
\hline \multirow[t]{3}{*}{1.} & Peran suami & & \\
\hline & a. Baik & 70 & 70 \\
\hline & b. Kurang baik & 30 & 30 \\
\hline \multirow[t]{3}{*}{2.} & Pengetahuan & & \\
\hline & a. Baik & 61 & 61 \\
\hline & b. Kurang baik & 39 & 39 \\
\hline \multirow[t]{4}{*}{3.} & Sikap suami & & \\
\hline & a. Mendukung & 55 & 55 \\
\hline & b. Kurang mendukung & 45 & 45 \\
\hline & Akses informasi & & \\
\hline \multirow[t]{3}{*}{4.} & a. Baik & 57 & 57 \\
\hline & b. Kurang baik & 43 & 43 \\
\hline & Total & 100 & 100 \\
\hline
\end{tabular}

Berdasarkan tabel 2 diketahui bahwa sebanyak $70 \%$ suami mempunyai peran yang baik dalam pencegahan BBLR, $61 \%$ suami berpengetahuan baik, $55 \%$ suami mempunyai sikap mendukung serta
$57 \%$ suami mempunyai akses informasi yang baik.

b. Analisis Bivariat

Analisis bivariat dengan uji chi square didapatkan hasil sebagai berikut:

Tabel 3. Hasil analisis bivariat

\begin{tabular}{|c|c|c|c|c|c|c|}
\hline \multirow[t]{3}{*}{ Variabel } & \multicolumn{4}{|c|}{ Peran Suami } & \multirow[t]{3}{*}{ Nilai p } & \multirow[t]{3}{*}{ Keterangan } \\
\hline & \multicolumn{2}{|c|}{ (baik) } & \multicolumn{2}{|c|}{ (kurang baik) } & & \\
\hline & $\mathbf{n}$ & $\%$ & $\mathbf{n}$ & $\%$ & & \\
\hline Pengetahuan suami & & & & & & Berhubungan \\
\hline - Baik & 48 & 78,7 & 13 & 21,3 & 0,032 & \\
\hline - Kurang baik & 22 & 56,4 & 17 & 43,6 & & \\
\hline Sikap suami & & & & & & Tidak \\
\hline - Mendukung & 43 & 78,2 & 12 & 21,8 & 0,07 & Berhubungan \\
\hline -Kurang mendukung & 27 & 60,0 & 18 & 40,0 & & \\
\hline Akses informasi & & & & & & Berhubungan \\
\hline - Baik & 46 & 80,7 & 11 & 19,3 & 0,014 & \\
\hline - Kurang baik & 24 & 55,8 & 19 & 44,2 & & \\
\hline
\end{tabular}


Tabel 3 menunjukkan dari hasil analisis bivariat, variabel yang berhubungan dengan peran suami dalam pencegahan BBLR adalah pengetahuan suami dan akses informasi karena mempunyai nilai $\mathrm{p}$ $<0,05$. Selanjutnya untuk analisis multivariat ketiga variabeldiikutkan dalam analisis karena mempunyai nilai $\mathrm{p}<0,25$

Tabel .4. Hasil Analisis Multivariat c. Analisis Multivariat

Analisis multivariat dilakukan untuk menganalisis secara bersama sama antara pengetahuan, sikap, dan akses informasi dengan peran suami dalam pencegahan BBLR dan hasilnya hanya faktor akses informasi yang berpengaruh

\begin{tabular}{llll}
\hline Variabel & p value & Exp. B & Keterangan \\
\hline $\begin{array}{l}\text { Akses } \\
\text { informasi }\end{array}$ & 0,008 & 3,31 & Berpengaruh \\
\hline
\end{tabular}

Tabel 4 menunjukkan dari hasil analisis multivariat hanya satu variabel yang berpengaruh terhadap peran suami dalam pencegahan BBLR yaitu akses informasi.

Informasi kesehatan dan media informasi dapat mempengaruhi perilaku pencegahan. Semakin banyak informasi kesehatan yang didapatkan seseorang akan memberikan perubahan perilaku yang bersifat tetap. Individu dapat memperoleh informasi melalui orang terdekat maupun melalui media, baik cetak maupun elektronik (Gielen dan Mc Donald, 2008). Penelitian Shahjahan et al.,(2013) menunjukkan adanya hubungan antara akses media informasi (koran, radio dan televisi) dengan partisipasi pria dalam pelayanan reproduksi.Penelitian ini sejalan dengan penelitian Shahjahan et al., (2013) yang menyatakan bahwa akses informasi berhubungan dengan peran pria dalam pelayanan reproduksi. Memiliki akses informasi yang baik dapat mempengaruhi pria untuk menggunakan KB dan akan 
meningkatkan komunikasi antara suami dan istri. Paparan informasi pada pria akan meningkatkan penggunaan kontrasepsi dan perubahan perilaku lainnya.Penelitian ini juga sejalan dengan penelitian Zamawe (2015) yang menyatakan bahwa ada pengaruh media massa terhadap keterlibatan suami dalam kesehatan ibu. Suami dari wanita yang mendapat informasi dari program radio lebih mungkin untuk berpartisipasi dalam perawatan antenatal, untuk terlibat dalam melahirkan dan untuk berpartisipasi dalam perawatan postnatal dibanding dengan suami yang tidak mendapat informasi melewati radio.

$$
\text { Notoatmodjo }
$$

menyatakan bahwa ada atau tidak adanya informasi mengenai kesehatan atau fasilitas kesehatan akan mempengaruhi perilaku seseorang terhadap fasilitas kesehatan. Semakin sering diberikan informasi akan terjadi perubahan perilaku yang bersifat tetap. Menurut Gielen dan Mc Donald (2008), informasi kesehatan dan media informasi dapat mempengaruhi perilaku pencegahan. Semakin banyak informasi kesehatan yang didapatkan seseorang akan memberikan perubahan perilaku yang bersifat tetap.

Hasil analisis multivariat menunjukkan bahwa pengetahuan tidak berhubungan secara bersama sama dengan peran suami dalam penccegahan BBLR. Hasil penelitian ini tidak tsejalan dengan penelitian Suryatidkk., (2012) yang menyebutkan bahwa terdapat hubungan bermakna antara pengetahuan suami terhadap partisipasi suami dalam kehamilan. Ikhsan (2012) juga menyatakan adanya hubungan pengetahuan suami dengan partisipasi suami dalam kehamilan $(\mathrm{p}=0,013)$. Tidak adanya hubungan pengetahuan suami dengan peran suami dalam pencegahan BBLR dikarenakan dari 61 suami yang berpengetahuan baik masih terdapat $46,5 \%$ yang mempunyai akses informasi kurang baik, 37,7\% memiliki sikap kurang mendukung serta $54,4 \%$ mempunyai penghasilan I bawah UMR. Keadaan ini yang menyebabkan walaupun pengetahuan suami sudah baik akan tetapi masih belum memiliki peran yang baik dalam pencegahan BBLR.Hasil 
multivariat menunjukkan bahwa sikap tidak berpengaruh terhadap peran suami dalam pencegahan BBLR. Hasil ini bertentangan dengan penelitian Keswara dkk.,(2012) menunjukkan adanya hubungan antara sikap dengan partisipasi suami dalam menjaga kehamilan istri $(\mathrm{p}=0,000)$. Sikap yang mendukung akan mendorong suami dalam berpartisipasi menjaga kehamilan istrinya. Tidak adanya hubungan sikap dengan peran suami dalam pencegahan BBLR dikarenakan dari 55 orang yang mempunyai sikap mendukung , 70,9\% memiliki keluarga besar, $36,4 \%$ mempunyai akses informasi kurang baik serta $52,7 \%$ berpenghasilan rendah. Tingkat penghasilan akan mempengaruhi perilaku kesehatan seseorang. Tingkat penghasilan yang tinggi akan mendukung individu dalam memenuhi semua kebutuhannya untuk menunjang kesehatannya (Maulana, 2009). Penelitian Shahjahanet al., (2013) menyatakan bahwa ada hubungan yang bermakna antara pendapatan dengan peran pria dalam pelayanan kesehatan reproduksi.

\section{SIMPULAN DAN SARAN}

Faktor yang berhubungan dengan peran suami dalam pencegahan BBLR adalah akses informasi. Pengetahuan dan sikap tidak mempengaruhi peran suami dalam pencegahan BBLR di Wilayah Kerja Puskesmas II Sumbang dan Kedungbanteng.

Saran bagi pihak Puskesmas II Sumbang dan Puskesmas Kedungbanteng untuk dapat mengoptimalkan akses informasi berupa penyediaan media massa (penyediaan leaflet, poster, sticker dan sebagainya) mengenai pencegahan BBLR serta melibatkan suami dalam intervensi kesehatan seperti konseling dan penyuluhan terkait pencegahan BBLR sehingga dapat meningkatkan kesadaran suami dalam upaya pencegahan BBLR. Bagi para suami agar lebih aktif mengakses informasi mengenai BBLR dari berbagai sumber dan menggali informasi mengenai kondisi kehamilan ibu serta cara perawatan ibu hamil dari Bidan Desa sehingga dapat meningkatkan pengetahuan suami mengenai BBLR. 


\section{DAFTAR PUSTAKA}

Alawiyah, F., 2014, Hubungan Dukungan Suami dengan Kelengkapan Kunjungan Antenatal pada Ibu Hamil Trimester III di Puskesmas Mergangsan KotaYogyakarta tahun 2014.Artikel Ilmiah. Fakultas Kesehatan Masyarakat Universitas Malahayati, Bandarlampung.

BKKBN, 2007, Keluarga Berencana dan Kontrasepsi, Pustaka Sinar Harapan, Jakarta.

Dinkes Banyumas, 2015, Profil Kesehatan Kabupaten Banyumas tahun 2014, Dinas Kesehatan kabupaten Banyumas, Banyumas.

Ditekemena, et al.,2012, Determinants of Male Involvement in Maternal and Child Health Services in sub-Saharan Africa: a review. Journal of ReproductiveHealth, 9(32): $1-8$

Gielen, A.C. dan Mc Donald E.M., 2008, The Preceed-Proceed Planning Model, Jossey Bass, California.

Ikhsan , K.N., 2012, Hubungan Tingkat Pengetahuan Suami dengan Partisipasi Suami terhadap Kehamilan pada Salah Satu Bidan Praktel Swasta (BPS) di Desa Sindangherang Kecamatan Panumbangan Kabupaten Ciamis, Cakrawala Galuh Journal, 2(2) .

Kemenkes RI, 2015, Profil Kesehatan Indonesia 2014, Kementerian Kesehatan Republik Indonesia, Jakarta.

Kemenkes RI, 2013, Riset Kesehatan Dasar (Riskesdas) 2013, Badan Penelitian dan Pengembangan Kesehatan Kementerian Kesehatan, Kemenkes RI, Jakarta.

Keswara, U.R., Karhiwikarta, W. Dan Bustami, 2012, Faktor-faktor yang Berhubungan dengan Partisipasi Suami dalam Menjaga Kesehatan Kehamilan Istri di Puskesmas Kota Bandar, Artikel Ilmiah, Fakultas Kesehatan Masyarakat Universitas Bandarlampung.

Lewis, et al, 2015, The Role of Husbands in Maternal Health and Safe Childbirth in Rural Nepal: a Qualitative Study, BMC Pregnancy and Childbirth,15 (162) :1-10.
Maulana, H.D.J., 2009, Promosi Kesehatan, EGC, Jakarta.

Notoatmodjo, S., 2010, Ilmu Perilaku Kesehatan, Rineka Cipta, Jakarta.

Puskesmas Kedungbanteng, 2016, Profil Kesehatan Puskesmas Kedungbantengtahun 2015, Puskesmas Kedungbanteng, Banyumas.

Puskesmas Sumbang II, 2016, Profil Kesehatan Puskesmas Sumbang II tahun 2015, Puskesmas Sumbang II, Banyumas.

Proverawati., Siti A., S., 2010, BBLR : Berat Badan Lahir Rendah, Nuha Medika, Yogyakarta.

Shahjahan, Md., et al, 2013, Determinants of Male Participation in Reproductive Healthcare Services: a Cross-sectional study, Journal of ReproductiveHealth, 10(27): 1-6. Suryati, Y., Oyoh dan Dwijayanti, 2012, Hubungan Pengetahuan Suami dengan Partisipasi Suami terhadap Kehamilan di Balai Pengobatan Sumber Sehat Marga Asih Kabupaten Bandung, Jurnal Kesehatan Kastika,2 (2) : 1- 8.

WHO, 2013, Care Of The Preterm And/Or Low-Birth-Weight Newborn. http://www.who.int/maternal_child_adolesce nt/topics/newborn/care_of_preterm/en/. Diakses pada tanggal 4 Maret 2016.

WHO, 2014, Global Nutrition Targets 2025: Low Birth Weight Policy Brief , World Health Organization, Geneva.

Zamawe, C., Banda , M dan Dube, A., 2015, The Effect of Mass Media Campaign on Men's Participation in Maternal Health: A Cross-Sectional Studi in Malawi, Bio Medical Central Journal: Reproductive Health, 12 